\title{
ARE CONFLICTING REFERENCE-FIXING INTENTIONS POSSIBLE? REPLY TO MARTONE ${ }^{1}$
}

\author{
MARIO GÓMEZ-TORRENTE \\ https://orcid.org/0000-0002-5957-6544 \\ Instituto de Investigaciones Filosóficas \\ Universidad Nacional Autónoma de México (UNAM) \\ Mexico City \\ Mexico \\ mariogt@unam.mx
}

\author{
Article info \\ CDD: 401

\section{Keywords \\ Reference-Fixing Intentions \\ Demonstratives \\ Conflicting Intentions}

Received: 01.10.2020; Accepted: 17.10.2020

https://doi.org/10.1590/0100-6045.2020.V43N4.MM

\begin{abstract}
Filipe Martone argues that reference-fixing intentions where the intended object is represented by means of a description can never fix the reference of a demonstrative, and that a speaker, as a matter of empirical fact, never has simultaneous perceptual and non-perceptual reference-fixing intentions that she can intend as fixing the reference of a demonstrative. In this note I reject Martone's arguments for these claims.
\end{abstract}

\footnotetext{
${ }^{1}$ Support from the research project no. PIDPID-107667GB-I00 of the Spanish Ministry of Science and Innovation is gratefully acknowledged.
} 
Conflicting reference-fixing intentions have seemed to many authors (including myself in Roads to Reference) to present a problem for a theory of the determination of the reference of several kinds of expressions. It's not entirely unusual to find examples of uses of demonstratives, as well as of introductions of proper names and natural kind nouns, where the relevant speaker appears to have two or more reference-fixing intentions that don't lead to one same thing, and in fact that often lead to different things, there being no such thing as the thing that the speaker intends to refer to with his/her demonstrative, name, or natural kind noun. Nevertheless, in some of these examples one of the conflicting intentions appears to trump the others, so that the relevant expression appears intuitively to refer to the thing that is the object of that intention. An example involving a demonstrative use from Roads to Reference, that Filipe Martone (2020) focuses on, is as follows: you and I are watching a soccer game where one of the players is obviously more skilled than the others; at the same time as I follow his impressive maneuvers in the field, something makes me think, falsely, that he is my bright philosophy of language student. I say (and the guy is so good that you have no trouble seeing whom I refer to) That's a really good player, apparently with what we would normally describe as the intention to refer to the player as represented by my very perception of him, and also with what we would normally describe as the intention to refer to my bright philosophy of language student as represented descriptively, by the very description "my bright philosophy of language student". Even though, unbeknownst to me, my intentions are in conflict, my use of "that" appears intuitively to have the soccer player as its conventional referent-not my bright student. This goes against what I call the Simple Intention theory of the reference of demonstratives: 
(Simple Intention) A use of a demonstrative refers to an object o iff o is the thing that the utterer intends to refer to with his/her use (Gómez-Torrente (2019), 29).

For this Simple Intention theory implies that my use of "that" did not refer at all, there being no single object of the reference-fixing intentions that underlay my use. In Roads to Reference, on the other hand, I postulate the existence of a reference-fixing convention to the effect that in cases where among the conflicting reference-fixing intentions determining some thing or other there is just one that is perceptual, the conventional referent of the demonstrative at stake is the object of this perceptual intention; the existence of such a convention accounts for the linguistic intuition that my intention to refer to the player overrides my intention to refer to my student.

Martone wants to defend the Simple Intention theory by arguing that at least typical cases of what appear to be conflicting reference-fixing intentions are in fact impossible, contrary to widespread opinion. According to Martone, descriptive reference-fixing intentions are "attributive", i.e. "intentions to refer to an object satisfactionally, as the satisfier of some condition", as opposed to genuinely "referential" "in the sense of Donnellan", i.e. "intentions to refer to an object one is already thinking about", paradigm cases of "referential" intentions being what I call perceptual intentions to refer. ${ }^{2}$ But on Martone's view,

2 The reader may recall that Donnellan employs originally the terminology "referential"/ "attributive" in order to make a distinction between uses of descriptions, and in such a way that one same description can have both referential and attributive uses depending on the context of utterance. Usually the distinction is seen as one between uses that somehow express a particular 
one cannot use a demonstrative like 'that' with attributive intentions in this way. Demonstratives are "designed" to exploit some contextually given relation between the speaker and an object; this is what makes them demonstrative and directly referential expressions. In other terms, the point of a demonstrative is to demonstrate, and I can only demonstrate what is already given to my cognition,

for example perceptually. As noted above, in the player/student example, my intention to refer to my bright philosophy of language student by the very description "my bright philosophy of language student" is certainly descriptive, so it follows from Martone's view that I "cannot use" the demonstrative "that" with that descriptive intention to refer-he also speaks of the example of the

content involving the described thing and uses that somehow express a general content not involving that thing. (See e.g. Gómez-Torrente (2015).) It might be noted that according to recent followers of Donnellan, referential uses of descriptions directly refer to the described object, though they must satisfy the description as well, and can unproblematically be used to fix the referents of corresponding uses of simple demonstratives. I might thus claim that my use of "my bright philosophy of language student" in the player/student case is referential and thus seek a way out of Martone's criticism. But I won't follow this line of reply, both because I doubt that the Donnellanian view of descriptions is correct (see again Gómez-Torrente (2015)) and because, as I will soon explain in the main text, I don't think there is any real obstacle preventing the fixing of the reference of demonstratives by means of strictly attributive uses of descriptions. 
player/student as describing "an impossible situation". Now, of course I can, in an obvious sense, use the demonstrative with whatever intention I want, but Martone's view appears to be, if he allows me to phrase his intentions more exactly, that if I do so I am committing a mistake that must somehow be condemned by the convention(s) governing demonstrative reference. For example, that convention, on Martone's intended view, must presumably be something along these lines:

(Non-Attributive Simple Intention) A use of a demonstrative refers to an object o iff o is the thing that the utterer, by means of a referential (non-attributive) intention, intends to refer to with his/her use.

Then, there being no more than one "referential" ("nonattributive") intention involved in the example, the object of this intention (the player) will come out as the referent of my use of "that" according to Non-Attributive Simple Intention, and the object of the other intention will come out as fully irrelevant. To the objection that "I can think things like well, the tallest mountain in South America... that's where I wanna go for vacation", where it seems that "I use the word 'that' to refer to that mountain I thought about" and that "this would show that it is possible to couple a demonstrative with an attributive intention", Martone replies that

it seems to me that the word 'that' in the second part of my thought is not being used as a demonstrative. This looks like an anaphoric use: 'that' is coindexed with the antecedent description, and it inherits its interpretation from the description... the content of 'that' is 
equivalent to the content of 'the tallest mountain in South America', and hence not a demonstrative.

While I think there is a true phenomenon underlying Martone's remarks here, the true picture of the situation is not one where descriptive (or "attributive") intentions cannot conventionally be used to fix the referents of uses of demonstratives. Let's think first about Martone's claim that since the content of "that" in his example is equivalent to the content of "the tallest mountain in South America", this shows that "that" cannot be used as a demonstrative when its reference is intended to be fixed by that description. Now, surely there may be anaphoric uses where "that" is somehow equivalent to the description to which it is linked; but Martone would need a more sweeping general claim, that whenever the reference of a use of "that" is intuitively designed to be fixed by a description, the use of "that" at stake will be equivalent to the description. And I think we can easily find examples where this is pretty evidently not so. Suppose after reading Naming and Necessity I engage in the following reflection: I have no idea what the tallest mountain in South America is. But anyway, Kripke makes it clear that the thing that is the tallest mountain in South America could have existed without being the tallest mountain in South America. And yet, as he also makes clear, it (/that) could not have existed without being it (/that)! My reflection (an application of one of Kripke's tests for rigidity to "the tallest mountain in South America" and then to a demonstrative use of "it" (and "that") intended to have its referent fixed by that very description) shows that "the tallest mountain in South America" is not rigid, while the demonstrative use of "it" (and "that") intended to have its referent fixed by that very description is rigid. Hence, the description and the demonstrative use do not have the same content, and in 
fact we get the strong suggestion that while "the tallest mountain in South America" has a descriptive content, the demonstrative use of "it" (and "that") directly refers to the mountain, whatever that mountain may be. A fortiori, there are uses of demonstratives intended to have their referents fixed by description and which do successfully get such referents - and which, if so, they do perforce get these referents via the operation of demonstrative referencefixing conventions. ${ }^{3}$

In my example (a mildly philosophical one, because it is designed to make very explicit the point about the difference in content between the description and the demonstratives), I, the speaker, have a purely descriptive epistemic contact with the tallest mountain in South America. I think Martone's intuition is driven by the true phenomenon that, typically, one does not fix the reference of one's demonstratives via descriptions with a very general content, the mere entertaining of which will normally put the entertainer in an at best distant epistemic contact with the described object. Uses of demonstratives are very often (though by no means exclusively) uses where the utterer is in fact "epistemically close" to the object referred to, and this is normally not the case with descriptions with a very general content. But "epistemic distance" is a matter of degree, even among descriptions, and the lesser the epistemic distance between description and described thing, the likelier it will be that we find demonstratives fixed by the description. The content of "the tallest mountain in South America" is indeed very general (even if presumably not completely general-South America is featured in that

\footnotetext{
${ }^{3}$ It may be worth recalling that the seminal Kaplan (1977) (in section XVII) contains a passionate defense of demonstrative (direct) reference fixed by description (even by epistemically "distant" descriptions).
} 
content somehow), but there are many other less extreme examples.

A somewhat less general but still descriptive content underlies the description "the squirrel that ate my peaches this morning", which identifies for me the squirrel that (I conjecture, as it happens truly) got into my kitchen this morning through the window that I had left open and made a mess with my fruit. If I say to my son That was a bungry squirrel, my use of "that" appears to refer unproblematically to the squirrel, presumably via a reference-fixing intention where the squirrel is represented by that description or a similar one-even if I haven't seen the squirrel at all. (And again my "that" is intuitively not equivalent with the description in question, as rigidity tests indicate.) For another example, suppose that my bright philosophy of language student is someone I have never met or seen; he attended the philosophy of language course that I just gave fully online because of the Covid-19 pandemic (true story!), and he was one of those students who never turned his video on during the virtual meetings or asked any questions, limiting himself to emailing me impeccable (electronic) answer sheets. My epistemic contact with the student is still slight, though intuitively closer than my contact with the mountain or with the squirrel in the previous examples. What I have is essentially a description of him with a not-so-general content, along the lines of "my bright philosophy of language student" or "the student who turned in those impeccable answer sheets in my online philosophy of language course". If I talk about the student's feats with a colleague and at some point I say He's good, my use of "he" again appears to refer unproblematically to the student, presumably via a reference-fixing intention where the student is represented by that description or a similar one. (And again my "he" is intuitively rigid, unlike the description.) 
Apparently even Martone thinks, without realizing it, that in some cases a use of "that" by a speaker refers to a certain thing via a descriptive reference-fixing intention even if the speaker has never been in any kind of close epistemic contact with the described thing. About the example of conflicting demonstrative intentions par excellence, the Agnew/Carnap example from Kaplan (1978), ${ }_{4}^{4}$ Martone says that "there is no reference failure nor indeterminacy". Presumably he says this because he thinks, with the writers who think that one of the conflicting intentions in this case overrides the other, that Kaplan's "that" refers to the picture of Agnew. ${ }^{5}$ But Kaplan has never seen the picture of Agnew, and if anything makes his use of "that" refer to that picture, it must be his descriptive intention to refer to the picture bebind me, the picture on that wall, or something like that. Surely descriptions with epistemically close particular elements in their presumable contents, but descriptions nonetheless, and descriptions of an object that Kaplan has no close epistemic contact with. (On the other hand, Kaplan's intention to refer to Carnap's picture may be taken to be memorial, and thus epistemically less distant.) Now, it may be good to recall that my view of this example in Roads to Reference is that Kaplan's "that" is referentially indeterminate (though this has been obscured

\footnotetext{
${ }^{4}$ In this famous example, Kaplan, without looking back, points to a place on his office's wall behind him where a picture of Carnap used to hang, and says That is a picture of one of the greatest philosophers of the twentieth century. When he does this, he has not realized that someone has replaced the portrait of Carnap with one of the politician Spiro Agnew.

${ }^{5}$ Ricardo Mena thinks that Kaplan's "that" refers to Carnap's picture, but that's because Mena thinks that it refers to both pictures, which is evidently not Martone's view; see my reply to Mena in this issue.
} 
for many authors by a number of reasons, including an inadequate focus on the intuitions of audiences who only know that Kaplan is pointing to the picture behind him and know little about his reference-fixing intentions or about the context of the utterance as a whole), so I would not use this case as an example of successful reference fixing of a demonstrative use by means of a descriptive referencefixing intention. But the fact that Martone's intuitions about the case pull him in this direction is significant, as it shows that they are not really consistent.

Though Martone focuses his efforts on his attempt to show that "attributive" reference-fixing intentions cannot fix the referents of demonstratives (that they cannot do so as a matter of convention, as I read him), he also argues briefly that, as a matter of non-conventional or empirical fact about the psychology of demonstrative utterances, a speaker cannot in general have both a perceptual referencefixing intention and a non-perceptual reference-fixing intention underlying one same use of a demonstrative. Thus, for example, suppose we modify the player/student example so that I imagine myself having both the perceptual reference-fixing intention above and what we would normally describe as the intention to refer to my bright philosophy of language student as represented by a memory I have of having seen him in a ("offline"!) class (in this case also a referential, non-attributive intention in Martone's view). According to Martone, I cannot really imagine such a thing, and if I think I do, I'm confused. Underlying a particular use I make of a demonstrative, Martone conjectures, I can have a specific reference-fixing perceptual intention, or a specific reference-fixing memorial intention, but not both, so in either case Non-Attributive Simple Intention applies, yielding a referent (the player in the former case and the student in the latter case). On the other hand, another significant conjecture of Martone is 
that underlying a particular use I make of a demonstrative I can have two or more conflicting reference-fixing perceptual intentions (as in my tree example from Roads to Reference ${ }^{\emptyset}$ ); in such cases, Martone concedes that "reference really seems indeterminate".

But why would cases like the imagined one of conflicting perceptual and memorial intentions be impossible as a matter of fact? Martone says:

In order to exploit a mind-object connection in the use of a demonstrative, it seems that we need to attend to the object... In order for the soccer player case to work, it should be possible to attend to an object in perception and to an object in memory simultaneously in the episode of tokening the demonstrative... the use of the demonstrative would try to exploit both kinds of attention at the same time. But this seems highly implausible to me. Attention is a limited resource. It is hard enough to shift attention quickly from one sensory modality to another, or even between objects in a single sensory modality, let alone attend simultaneously to two objects via different kinds of attention. Shifting attention inward, to browse our memory, is too demanding to our cognition to allow for simultaneous perceptual attention... As the soccer player case is described, it seems clear

${ }^{6}$ In the example, a speaker, while touching a tree and seeing a different one that she thinks is the same, intends (perceptually) to refer to the tree she is touching and to the tree she is seeing, with her use of 'this' in This is a tree with such a nice trunk (see GómezTorrente (2019), 42). 
that my attention is focused on the player, and not on the brightest student. This is why, according to our intuitions, I refer to the perceptually given player, not to the brightest student.

I think the view that Martone wishes to push is fraught with difficulties. First, I doubt that the case of a perceptually presented object and a memorially presented object is uncontroversially different from the case of two objects presented perceptually by different sensory modalities. As far as I can tell by introspection in my own case, I can somehow attend simultaneously to two objects presented perceptually by different modalities (my hand as seen and my foot as felt, for example), but I can equally attend simultaneously to a perceptually presented object and a memorially presented object (my deceased cat's plate seen on the floor and my cat as I remember her). In any case, I doubt that Martone can marshal more than flimsy evidence for his claims about simultaneous attention.

But second, and more important, I don't think his claim that any and all operating reference-fixing intentions ought to be simultaneous with "the episode of tokening the demonstrative" withstands close scrutiny. Presumably with this claim we are back, not to a matter of psychological fact, but to some kind of normative fact about how the reference of a demonstrative ought or could be conventionally fixed by the underlying reference-fixing intentions: Martone's idea appears to be that any referencefixing intention not simultaneous with the tokening or utterance of the demonstrative cannot (normatively) fix the demonstrative's referent. I think this is just clearly not true, and that it can be seen fairly non-controversially that it is false by coupling attention to our linguistic intuitions and to what we might call the phenomenology of demonstrative 
utterance. Suppose I explicitly form the intention of talking about my dead cat while I remember her. The very thought of her makes me a bit sad and I don't say anything immediately, but as I recompose after a few seconds, I utter She was a sweet cat (true story!). As I introspect on the phenomenology of such an utterance, I don't find anything I can identify as the forming of a new intention to refer that is simultaneous with my utterance. Furthermore, my linguistic intuitions tell me that even if such simultaneous intention is absent, the existence of the earlier intention is all that's needed to endow my utterance with a referent (my dead cat). The point can perhaps be made even clearer if we reflect on the phenomenology of a series of utterances that linguistic intuition tells us all have the same referent. If I say She was a sweet cat. And she was so tidy and so well-behaved. Ah, and I remember that time when she tried to console me when she noticed I was feeling down... Surely no occurrent referencefixing intention is taking place in my mind as I utter the fourth "she" in this little discourse, but it certainly refers to my cat.

Clearly the relevant reference-fixing intention underlying a demonstrative utterance is often formed before the utterance, either explicitly or, probably even more often, in some implicit way that need not be reflected in the speaker's conscious mental life and may be merely constituted by the appearance of appropriate dispositions in her (for example, dispositions to reveal what thing she meant to be talking about with her utterance, via a description, a name, a demonstrative, etc.). Again the phenomenology of demonstrative utterance suggests this, as the vast majority of our utterances of demonstratives clearly don't involve anything like the conscious forming of simultaneous reference-fixing intentions. This is also true of utterances underlain by perceptual reference-fixing intentions: even if I am perceiving the object referred to as 
I make my utterance, the forming of my intention of talking about it need not be simultaneous with the utterance, and in fact my introspection tells me that as I utter a demonstrative in such a case my reference-fixing intention may have been formed earlier in an explicit way, or doesn't reach conscious level and subsists in me constituted by the existence of appropriate dispositions. To see this, it may again be useful to think of a little discourse pronounced by me as I watch the brilliant maneuvers of the player I mistake for my student: That's a really good player. He dribbles at great speed, he kicks the ball so hard... and he is a team player as well! Surely no occurrent reference-fixing intention is taking place in my mind as I utter the fourth "he" in this little discourse (even if I have been perceiving him throughout my whole series of utterances), but it certainly refers to the brilliant player,

The upshot is that, as far as I can tell, successful reference-fixing intentions underlying a demonstrative utterance need not be simultaneous with the production of the utterance, against Martone's conjecture. If this is so, no obstacle has been uncovered to the possibility of two or more conflicting reference-fixing intentions (descriptive, memorial, perceptual, etc.) lying behind the utterance of a demonstrative, and the problem of conflicting intentions remains as pressing as ever as a problem for theorists of demonstratives.

\section{REFERENCES}

Gómez-Torrente, M. (2015), "Quantifiers and Referential Use", in A. Torza (ed.), Quantifiers, Quantifiers, and Quantifiers: Themes in Logic, Metaphysics, and Language, Springer, Dordrecht, 97-124. 
Gómez-Torrente, M. (2019), Roads to Reference. An Essay on Reference Fixing in Natural Language, Oxford University Press, Oxford.

Kaplan, D. (1977), "Demonstratives”, in J. Almog, J. Perry, and H. Wettstein (eds.), Themes from Kaplan, Oxford University Press, Oxford, 1989, 481-563.

Kaplan, D. (1978), "Dthat", in P. Cole (ed.), Syntax and Semantics, Volume 9: Pragmatics, Academic Press, New York, 221-43.

Martone, F. (2020), "Is the Problem of Conflicting Intentions a Genuine Problem? Some Remarks on Gómez-Torrente's Roads to Reference", Manuscrito, this issue.

$(\mathrm{cc}) \mathrm{BY}$ 